\title{
Rootstocks induce shifts in tree vigor, yield and berry quality of 'Summer Black' grapevines
}

\author{
Yonggang Yin, Nan Jia, Minmin Li, Changjiang Liu, Junwei Yuan, Bin Han, Yan Sun, Shengjian Zhao and \\ Zijuan Guo \\ Institute of Changli Fruit Tree, Hebei Academy of Agricultural and Forestry Sciences, Changli, Hebei, China
}

\begin{abstract}
Summary
The agronomic performances of grape (Vitis vinifera L.) cv. 'Summer Black' vines on different resistant rootstocks including '101-14M', '110R', '188-08', '5BB', '5C', 'Beta' and 'S04' (with non-grafted vines as control) were evaluated to make dependable selections of rootstocks for cultivation. Tree vigor, fruit yield and berry quality related traits of eight combinations were assessed over three consecutive years. Scion vigor was improved by 'Beta' which greatly increased mature shoot length (MSL), and by 'S04' which distinctly enlarged scion trunk cross sectional diameter (TCD). Vines were remarkably productive on 'S04', while yield was restrained on '101-14M'. Cluster mass (CM) was maximal on '188-08', minimal on ' $5 \mathrm{C}$ ', and berry mass (BM) was maintained by '188-08', '5BB' and 'S04'. Grape berries on '101-04M' obtained total soluble solids (TSS) highly close to that of non-grafted vines. Overall, trees on ' $5 \mathrm{BB}$ ' and ' $5 \mathrm{C}$ ' acquired similar berry qualities (size, chemical traits and texture), yields and growth vigor to the control vines, and they were preferentially recommended for grafting cultivation of 'Summer Black' grapevines.
\end{abstract}

Keywords

berry quality, table grape, triploid, vigor, Vitis vinifera, yield components

\section{Introduction}

Grape (Vitis vinifera L.) as one of the major fruit crops plays an important role in agricultural economy. In 2018, total area of 7.2 million hectares produced 79.1 million tons of grape, and nearly $17 \%$ of that was produced in China (FAO, 2020). Around 540 thousand hectares of harvest area covered by fresh fruits (Wang et al., 2017) and high consumption of 10.73 million tons (USDA, 2019) reveals booming consumer demand in China.

Grape cultivation confronts lots of potential dangers such as salinity caused by irrigation, sudden cold injury, increased rainfall and attacks from pests and pathogens, which would cause economic losses and even vine death. Rootstocks were first used for protecting vine roots against the devastating root louse phylloxera, then were widely used in vine grafting to resist biological stresses, e.g., nematode and crown gall (Ferris et al., 2012; Roh et al., 2003), and abiotic stresses such as salinity (Yuan et al., 2019), acidity (Conradie, 1983), lime (Pavloušek, 2009), drought (Carbonneau, 1985), waterlogging (Dry, 2007) and low temperature (Gao et al., 2014). In addition to exert strong resistances to underground

\section{Significance of this study}

What is already known on this subject?

- 'Summer Black' is a very popular seedless grape cultivar in China for its good taste. Selection of suitable rootstocks would be beneficial for achieving good performances of cultivation.

What are the new findings?

- 'Summer Black' vines grafted on '5BB' and '5C' kept proper balance in vine vigor, berry quality and fruit yield, and those on 'SO4' were markedly productive.

What is the expected impact on horticulture?

- This study will provide credible preferences for choosing suitable rootstocks of 'Summer Black', and is significant in preventing vines from potential stresses which might be destructive.

stresses, rootstocks modify the scion performance, i.e., yield, berry quality and vine vigor (Wang et al., 2019). However, modifications vary from scion cultivars. '1103P', for instance, improved the vigor of 'Monastrell' (Romero et al., 2018), but reduced the size of 'Chardonnay' vines (Ferroni and Scalabrelli, 1995). Even the same scion/rootstock combination may present various performances (Sommer et al., 2001; Walker et al., 2010) due to the influence of soils, climates and viticulture practices on grapes.

In recent years, the utilization of resistant rootstocks is paid rising concerns by researchers in China (Gao et al., 2015; Zhang et al., 2012), and grafting a few wine grape varieties onto rootstocks were studied (Li et al., 2019a; Wang et al., 2019). Despite that rootstocks were realized with great potential in resisting stresses, most table grapes are still cultivated by cuttings due to the fortune of not having any phylloxera pest problems in the early years (http://www. fao.org/3/x6897e/x6897e05.htm). However, phylloxera has occurred in some provinces of China since 2005 (Zhang et al., 2010). To cope with the potential stresses, it appears indispensable to make reliable evaluations of rootstocks on agronomic performances of table grapes, especially the major varieties.

'Summer Black' ('Kyoto' × 'Thompson Seedless'), a classical seedless table grape cultivar released in 2000, is popular in both consumers and growers in China (Wang et al., 2017), and its planting area ran into nearly 20 thousand hectares in 2014 (Cheng et al., 2016). According to an internal communication by scientists from China Agriculture Research System, multiple varieties were found infected with root-knot nematodes in Southeast China in 2010, and 'Summer Black' was 
also infected in nematodes-containing soil. To minimize the unpredictable economic losses, it would be essential to evaluate the agronomic traits of this cultivar grafted on resistant rootstocks.

The objective of this study was to evaluate the tree vigor, fruit yield and berry quality of 'Summer Black' vines grafted on seven resistant rootstocks ('101-14M', '110R', '188-08', ‘5BB', '5C', 'Beta' and 'SO4'), with own-rooted vines (non-grafted) as control, over three consecutive years.

\section{Materials and methods}

\section{Experimental location and growing conditions}

The experiment was conducted in Kongzhuang experimental station $\left(39^{\circ} 42^{\prime} \mathrm{N}, 119^{\circ} 05^{\prime} \mathrm{E} ; 14 \mathrm{~m}\right)$ of Institute of Changli Fruit Tree, Qinhuangdao, China, within three years from 2015 to 2017. Changli is a major wine-producing region of which the climate is classified as type sub-humid continental monsoon. Meteorological data obtained from the local weather bureau was shown in Table 2. Soil in the block was typical 'loam', containing $2.38 \%$ organic matter and 1.38 $\mathrm{g} \mathrm{kg}^{-1}$ total nitrogen, and the $\mathrm{pH}$ was 6.52 .

\section{Materials, experimental design and vine training}

The mature scions of 'Summer Black' were grafted on hardwood cuttings of seven resistant rootstocks, i.e., '10114M', '110R', '188-08', '5BB', '5C', 'Beta' and 'SO4'. The descriptions and resistance characteristics of these rootstocks summarized from current studies (Audeguin et al., 2007; Carbonneau, 1985; Dry, 2007; Du et al., 2008; Gao et al., 2014; Roh et al., 2003; Sun et al., 2008; Yuan et al., 2019) were shown in Table 1 . Cleft grafting was conducted in early April of 2010, and the grafted seedlings were then bred as well as the own-rooted cuttings in a nursery for almost a month until they were transplanted in the field, at a spacing (vine $\times$ row) of $0.7 \times 4.0 \mathrm{~m}$. A completely randomized block design was used with three independent replicates. Each replicate included 10 vines.

The vines were trained by a trellis-training system with height of $1.8 \mathrm{~m}$, rows from north to south and growth direction to the east. Measurements were subsequently conducted from 2015 to 2017. 'Summer Black' vines sprouted naturally in mid-April and flowered in late May locally. Growth regulators are necessary in commercial cultivation of 'Summer Black' to solve problems of small berry, low fruit setting and incomplete coloring. Spica was treated with a dip of $20 \mathrm{mg} \mathrm{L}^{-1}$ $\mathrm{GA}_{3}$ during blossom, and with $40 \mathrm{mg} \mathrm{L}^{-1}$ of $\mathrm{GA}_{3} 12$ days later. Berries were initially colored in mid-July and clusters in complete maturation were harvested in late August when the berry color turned to dark purple black (harvest date of each season was shown in Table 2). Canes were pruned to leave 1-2 nodes. All the trees were buried to resist the cold winter. In addition, cultivation practices including watering irrigation, fertilization, pest and disease managements were based on regional normal standards during the trial. Weeds were mainly controlled by covering black plastic film on the ground, and a polyethylene screen was set to envelope the entire block to prevent birds' attack.

\section{Measurement of vine growth parameters}

Growth parameters of 10 vines for each replicate were measured a few days before pruning in October 2017. Scion trunk cross sectional diameter (TCD, the longest axes) $30 \mathrm{~cm}$ above the graft union (similar position on non-grafted vines was measured for reference), shoot basal diameter (the longest axes), and mature shoot length were measured using digital vernier calipers and tapelines. Nodes on mature part of shoots were counted.

\section{Yield calculation}

For yield estimation, the number of bunches per vine was recorded at harvest, and the mean weight of cluster was calculated by averaging 20 bunches randomly picked from 10 vines of each replicate. The yield was expressed as $t$ ha $^{-1}$ through unit conversion.

\section{Determinations of quality-related parameters}

Twenty berries with carpopodium were randomly cut off from both sunny and shady sides of each weighted bunch with scissors after harvest. The clusters and a subsample of 30 berries were weighted using an electronic balance of one-tenth accuracy. Both vertical and horizontal diameters

TABLE 1. Rootstocks and their responses to biotic and abiotic stresses.

\begin{tabular}{|c|c|c|c|c|c|c|c|c|c|}
\hline Rootstocks & Parentage & Origin & Phylloxera & Nematodes & $\begin{array}{c}\text { Crown } \\
\text { gall }\end{array}$ & Drought & Salinity & Coldness & $\begin{array}{l}\text { Water } \\
\text { stress }\end{array}$ \\
\hline $101-14 \mathrm{M}$ & V. riparia $\times V$. rupestris & France & $\mathrm{HR}$ & MR-LR & $\mathrm{R}$ & $S$ & $\mathrm{R}$ & $\mathrm{R}$ & $S$ \\
\hline $110 R$ & V. berlandieri $\times V$. rupestris & France & $\mathrm{HR}$ & S & S & HR & MR & LR & $H R$ \\
\hline $188-08$ & V. berlandieri $\times$ V. riparia & France & - & - & $\mathrm{R}$ & MR & LR & - & - \\
\hline $5 \mathrm{BB}$ & V. berlandieri $\times$ V. riparia & Austria & $\mathrm{HR}$ & $\mathrm{R}$ & MS & $S$ & MR & $H R$ & MR \\
\hline $5 \mathrm{C}$ & V. berlandieri $\times$ V. riparia & Hungary & $\mathrm{HR}$ & - & MS & - & MR & MR & LR \\
\hline Beta & V. riparia $\times$ V. labrusca & USA & $S$ & - & - & $S$ & MR & $H R$ & - \\
\hline SO4 & V. berlandieri $\times$ V. riparia & Germany & $\mathrm{HR}$ & LR & $S$ & $\mathrm{R}$ & $S$ & HR & HR, LR \\
\hline
\end{tabular}

Responses to stresses were listed as resistance $(R)$, high resistance $(H R)$, moderate resistance (MR), low resistance (LR), sensitivity $(S)$, moderate sensitivity (MS) based on descriptions in cited works.

TABLE 2. Meteorological data of the experimental field and harvest date of 'Summer Black' grape in 2015-2017.

\begin{tabular}{ccccc}
\hline Year & Mean temperature $\left({ }^{\circ} \mathrm{C}\right)$ & Precipitation $(\mathrm{mm})$ & Sunshine duration $(\mathrm{h})$ & Harvest date \\
\hline 2015 & 12.4 & 598.1 & $2,759.8$ & August 17 \\
2016 & 12.1 & 859.8 & $2,708.1$ & August 31 \\
2017 & 12.7 & 590.7 & $2,563.5$ & August 21 \\
\hline
\end{tabular}


of 10 berries randomly chosen from each repetition were determined as berry length (BL) and berry width (BW) with a digital caliper. 15 berry samples were juiced using a fresh squeeze juicer for total soluble solid (TSS) and titratable acid (TA) assay. The TSS and TA were determined thrice using digital hand-held refractometer (PAL-1, Atago, Tokyo, Japan) and fruit acidity meter (GMK-835F, G-WON Hitech Co., Ltd., Seoul, Korea) respectively with automatic temperature compensation. TSS was expressed in units of ${ }^{\circ}$ Brix. TA was presented as tartaric aid equivalent in percentage according to the National Standard of the People's Republic of China (GB/T15308-2006, 2006). Pulling resistance of carpopodium (PRC) and compression resistance of berry (CRB) were determined using a mechanical force gauge (NK-50, Algol Instrument Co., Ltd., Taiwan, China) according to the manual and listed as Newton (N). PRC was defined as the reading when carpopodium was separated from the berry and CRB was defined as the reading when berry was broken. Flesh hardness (FH) was determined by pressing a hand-held fruit hardness tester (KM-1, Takemura Electric Works, Tokyo, Japan) equipped with a cylinder type tip (diameter is $5 \mathrm{~mm}$ ) on the center of berry where skin was sliced. FH equals the tester reading $(\mathrm{kg})$ divided by tip area and expressed as $\mathrm{kg} \mathrm{cm}^{-2}$. The ratio of sugar to acid was expressed as TSS/TA, and the ratio of berry length to berry width namely berry shape index was expressed as BL/BW.

\section{Statistical analysis}

Data were processed by analysis of variance with SPSS 20.0 (SPSS Inc., Chicago, IL, USA), and the means were compared by Duncan multiple range test at $\mathrm{P}<0.05$. Additionally, principal component analysis (PCA) was applied to 14 traits of vigor, productivity and physicochemical attributes via XLSTAT statistical software version 2019 (Addinsoft, Boston, USA), which were evaluated by Pearson's correlation.

\section{Results}

\section{Vine growth}

Rootstocks had significant effects on scion TCD, wooden shoot length, number of nodes per shoot and internode length other than shoot basal diameter of scions according to the measurements in the vines' $7^{\text {th }}$ year (Table 3). Vines obtained the largest scion TCD on 'SO4', and smallest on
'110R' among all rootstocks. Mature shoot length, number of nodes per shoot of vines on 'Beta' were markedly higher than others, while those of vines on '188-08' were the lowest. No significant difference in any index was detected among trees on '101-14M', '110R' and own roots. '5BB' and '5C' showed a relatively intermediate effect on vine vigor, slightly higher than own roots.

\section{Fruit yield}

Both the rootstock and harvest season significantly influenced the fruit yield during each harvest season, while no significant variation was detected in interactions (Table 4). Higher precipitation in 2016 delayed the maturation and increased production, and lower yield in 2017 might be due to less sunlight. The average estimated productivity of eight combinations in trial ranged from 17.70 ('101-14M') to 21.06 t ha $^{-1}$ ('SO4') per year, and averaged $19.01 \mathrm{t} \mathrm{ha}^{-1}$ each season. Vines on 'SO4' maintained the highest production in all seasons, slightly higher than those on '188-08' and '110R' with average yield of 20.10 and $19.48 \mathrm{tha}^{-1}$ per season respectively, showing a stable yield efficiency. No distinct differences in average yield were found among own-rooted vines and grafted ones as on 'Beta', '5C' and '5BB', which indicated that these rootstocks did not affect the fruit yield statistically. The rootstock '101-14M', which kept low producing levels in the first two seasons, had the smallest average yield of 17.70 t ha ${ }^{-1}$ per year.

\section{Berry quality}

Variances in main effects of harvest season and rootstock were highly significant for most parameters related to berry quality averaged over the three years, but the rootstock effect is the factor explaining the larger part of the variance (except for BW, BL/BW and CRB), compared to the year and their interaction effects (Table 4).

Largest cluster mass was obtained from vines on '18808 ' with an average of $842.15 \mathrm{~g}$, secondly largest on 'SO4' with $804.83 \mathrm{~g}$, and smallest on '5C' with $679.37 \mathrm{~g}$, while trees grafted on rootstocks as '110R', '5BB', '101-14M', and 'Beta' exhibited no distinct differences in bunch weight from own-rooted vines. Fruit produced on own roots had the highest berry mass, which was not notably different from fruit produced on '188-08', '5BB', and 'SO4'. '5C' slightly decreased the berry mass, while ' $110 \mathrm{R}$ ' reduced the berry mass to a low-

TABLE 3. Scion TCD, shoot basal diameter, mature shoot length and number of nodes per shoot of grafted and own-rooted 'Summer Black' vines.

\begin{tabular}{llccc}
\hline Rootstock & $\begin{array}{c}\text { Scion TCD } \\
(\mathrm{mm})\end{array}$ & $\begin{array}{c}\text { Shoot basal diameter } \\
(\mathrm{mm})\end{array}$ & $\begin{array}{c}\text { Mature shoot length } \\
(\mathrm{cm})\end{array}$ & $\begin{array}{c}\text { Number of nodes } \\
\text { per shoot }\end{array}$ \\
\hline $101-14 \mathrm{M}$ & $36.98 \pm 3.58 \mathrm{bc}$ & $12.30 \pm 0.55 \mathrm{a}$ & $116.15 \pm 30.14 \mathrm{~b}$ & $11.56 \pm 2.23 \mathrm{~b}$ \\
$110 \mathrm{R}$ & $35.50 \pm 3.50 \mathrm{c}$ & $12.88 \pm 0.75 \mathrm{a}$ & $119.64 \pm 25.66 \mathrm{~b}$ & $12.04 \pm 2.16 \mathrm{~b}$ \\
$188-08$ & $37.35 \pm 6.00 \mathrm{bc}$ & $12.22 \pm 1.09 \mathrm{a}$ & $104.37 \pm 38.28 \mathrm{~b}$ & $12.00 \pm 3.22 \mathrm{~b}$ \\
5BB & $40.63 \pm 6.63 \mathrm{ab}$ & $12.91 \pm 0.93 \mathrm{a}$ & $120.10 \pm 28.42 \mathrm{~b}$ & $12.61 \pm 2.17 \mathrm{ab}$ \\
$5 \mathrm{C}$ & $37.65 \pm 5.42 \mathrm{bc}$ & $12.86 \pm 1.35 \mathrm{a}$ & $131.72 \pm 31.45 \mathrm{ab}$ & $12.67 \pm 2.32 \mathrm{ab}$ \\
Beta & $38.16 \pm 5.35 \mathrm{bc}$ & $12.34 \pm 0.76 \mathrm{a}$ & $151.04 \pm 23.78 \mathrm{a}$ & $14.50 \pm 2.61 \mathrm{a}$ \\
SO4 & $44.84 \pm 2.37 \mathrm{a}$ & $12.39 \pm 0.96 \mathrm{a}$ & $124.32 \pm 18.12 \mathrm{~b}$ & $13.81 \pm 1.4 \mathrm{ab}$ \\
Own-rooted & $36.11 \pm 2.77^{2}$ & $12.22 \pm 1.08 \mathrm{a}$ & $119.08 \pm 26.42 \mathrm{~b}$ & $11.73 \pm 2.50 \mathrm{~b}$ \\
\hline
\end{tabular}

Growth data were collected in the $7^{\text {th }}$ year $(2017)$ of vines and shown in 'means $\pm S D$ '. Different letters within a column for each trait indicate a significant difference according to Duncan's multiple range test at $p<0.05$.

1 Scion TCD: scion trunk cross sectional diameter.

${ }^{2}$ Data were collected on similar position as other grafted vines for reference. 


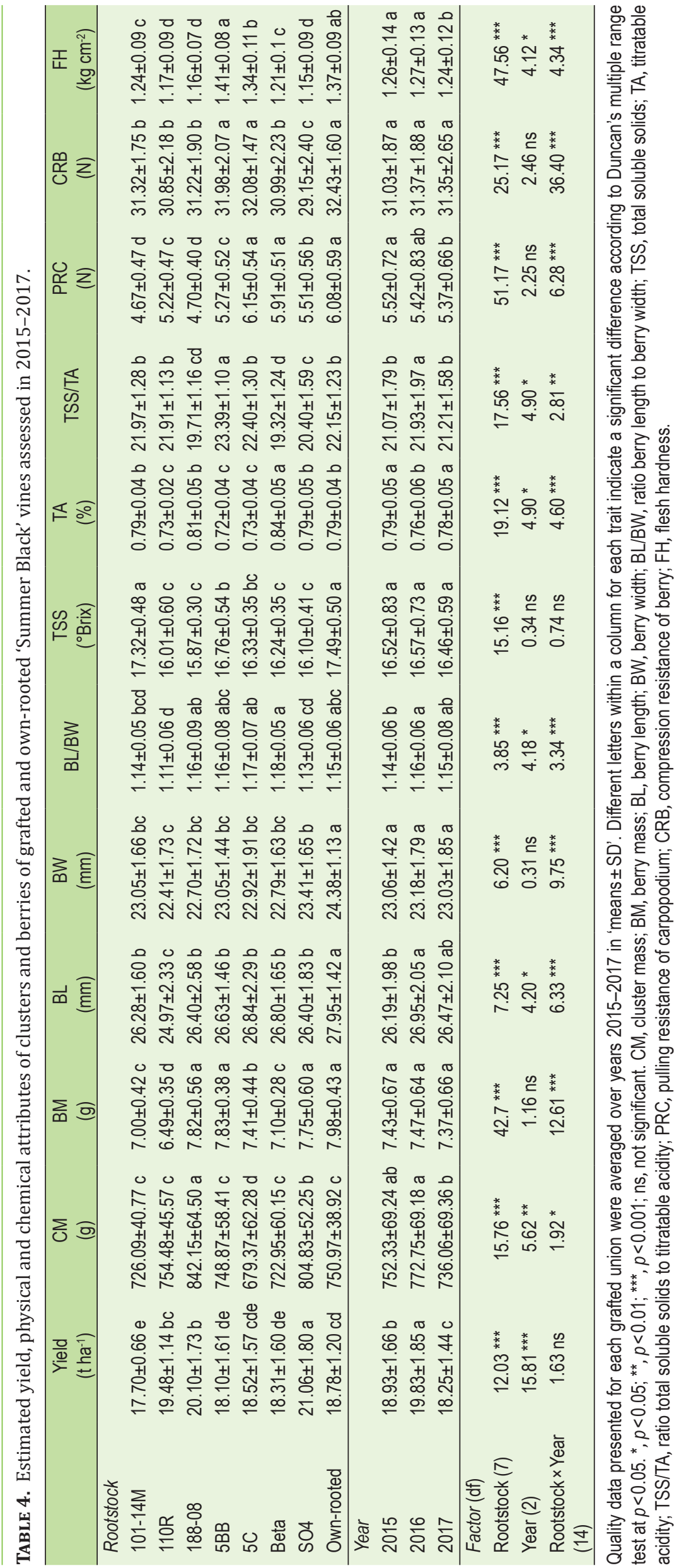


er level of $6.49 \mathrm{~g}$. Accordingly, similar trend to berry weight showed in berry length and width, merely own-rooted vines obtained the highest value. BL/BW ranged from 1.11 (on ' $110 \mathrm{R}$ ') to 1.18 (on 'Beta'), which indicated that berry shape was distinctly affected by rootstocks statistically even visually imperceptible.

The highest total soluble solids (TSS) contents were presented on 'own-roots' and '101-14M' with 17.49 and 17.32 'Brix respectively, followed by '5BB' with $16.76^{\circ}$ Brix, while the remaining rootstocks produced fruits in relatively lower TSS contents (Table 4). The tartaric acid (TA) content reached highest on 'Beta' with $0.84 \%$, lowest on ' $5 \mathrm{BB}$ ', '5C' and '110R', whereas other rootstocks produced fruits with moderate TA had no difference from own roots. The TSS/TA value ranged from a low of 19.32 for fruit produced on 'Beta' to a high of 23.39 for fruit produced on ' $5 \mathrm{BB}$ ', and fruits produced on '101-14M' and '110R' had TSS/TA of 21.97 and 21.91, which were higher than those on 'SO4' (20.4) and '188-08' (19.71), showing no significant difference from own-rooted vines.

Pulling resistance of carpopodium (PRC) and compression resistance of berry (CRB) are vitally related to grape transportation and preservation. The largest PRC obtained from fruits on own roots, ' $5 \mathrm{C}$ ' and ' $5 \mathrm{BB}$ ' $(32.43,32.08$ and $31.98 \mathrm{~N}$ respectively), and smallest on 'SO4' with $29.15 \mathrm{~N}$ (Table 4). Berries with highest compression resistance were produced on '5C', 'Own roots' and 'Beta', secondly on 'SO4'. '101-14M' and '188-08' significantly reduced the compression resistance of berry. Flesh hardness was highest in fruits grown on '5BB' ( $0.28 \mathrm{~kg}$ ), lowest on '110R', '188-08' and 'SO4' $(0.23 \mathrm{~kg})$, while that on own roots maintained a higher of $0.27 \mathrm{~N}$ than those on the rest rootstocks.

\section{Principal components analysis}

Principal components analysis (PCA) was performed on the data set of eight scion-rootstock combinations (including non-grafted vines) and 14 traits to provide overview visualization in a reduced dimension (Supplemental Information - Table S1). Features were extracted to seven principal components (PC), of which PC1 and PC2 accounted for $59.68 \%$ and PC3 explained an additional 19.05\%.
Specifically, $36.45 \%$ of the total variation was explained by PC1 (Figure 1A), which was positively correlated with berry qualities involving texture, flavor and size related properties: CRB, FH, TSS TSS/TA, BL, BW and BL/BW, and negatively correlated to yield production indexes (Yield and CM). On the other side, PC2, which accounted for $23.24 \%$ of the total variation (Figure 1A), was highly contributed by growth parameters ( $\mathrm{N}^{\circ} \mathrm{NpS}$ and $\left.\mathrm{MSL}\right)$ and TA with positive loadings and by TSS/TA with negative loading. PRC and BL/BW were on positive sides of both PC1 and PC2. In addition, CM, BW and especially BM were more relevant to PC3 (Supplemental Information - Table S1), while an overview of them could also be expressed effective in PC1 by PC2.

Although rootstocks tended to be scattered in examination of PC1 and PC2, regular clues could be found (Figure 1B). 'Own-rooted' performed better in FH, TSS, CRB and traits about berry size, followed by ' $5 \mathrm{C}$ ' and ' $5 \mathrm{BB}$ ' as a group, while '101-14M' was likely to produce high TSS and resultant TSS/TA merely. Vines grafted on 'Beta' generally obtained larger MSL and $\mathrm{N}^{\circ} \mathrm{NpS}$, as well as the TA of berries. 'SO4' and '188-08' were superior in improving yield and cluster mass. '110R' produced a relatively high yield, but also a high TSS/ TA of berry due to lower TA contents.

\section{Discussion}

In this study, most physiological attributes correlative to vine vigor, fruit yield and berry quality of 'Summer Black' grape were significantly affected by rootstocks.

Vine growing is much about balance. A study on 'Pinot noir' revealed that low vigor causes limited shoots growing and crop level, while high vigor promotes nutritional growth and reduces yield and quality (Cortell et al., 2008). In this trial, 'SO4', a medium scion vigor provider (Corso and Bonghi, 2014), produced especially larger scion TCD accumulated over 7 years than others, and performed moderately in wooden shoot length and number of nodes, which indicated that 'S04' may have a positive effect on vine vigor at least by promoting lateral growth of trunk. The vigor-increase impacts of 'SO4' were also exhibited on 'Chardonnay', 'Tempranillo' and 'Welschriesling' grapevines (Colldecarrera et

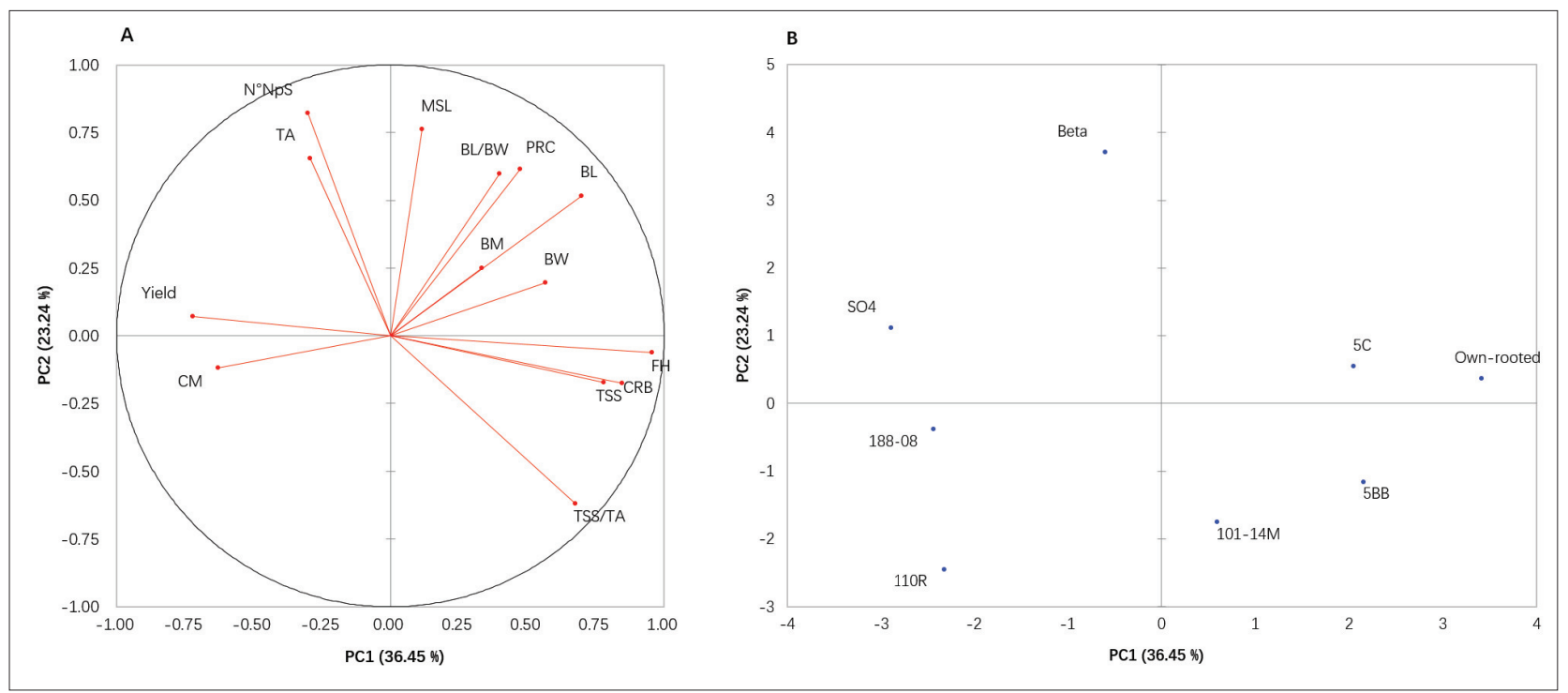

FIGURE 1. Plots of principal component analysis of 14 traits in eight scion/rootstock combinations of 'Summer Black' vines. Scores plot (A) and loadings plot (B). CM, cluster mass; BM, berry mass; BL, berry length; BW, berry width; BL/BW, ratio berry length to berry width; TSS, total soluble solids; TA, titratable acid; TSS/TA, ratio total soluble solids to titratable acid; CRB, compression resistance of berry; PRC, pulling resistance of carpopodium; FH, flesh hardness; MSL, mature shoot length; $\mathrm{N}^{\circ} \mathrm{NpS}$, number of nodes per shoot. 
al., 1997; Vršič et al., 2015). Contrarily, Novello et al. (1996) found that 'SO4' was negative in improving vigor of 'Erbaluce' grape. The differences in scion growth may be related to preferences of rootstocks to different nitrogen forms, 'SO4' and '140R' for instance, preferred calcium nitrate and ammonium sulphate respectively (Lang et al., 2018). In addition, rootstock 'Beta', as a primary cold-resistant variety in Northern China with vigorous roots, performed optimally on wooden shoot length as the longitudinal growth, and had the maximum nodes. Unfortunately, 'Beta' was not recommended in phylloxera-prone areas (Du et al., 2008).

Rootstocks had been reported to be positive (Satisha et al., 2010), non-effective (Sultan, 2016) and even negative (Sommer et al., 2001) in improving scion yield. Indeed, the yield of 'Summer Black' was distinctly affected by rootstocks on all mentioned levels. 'SO4' was reported with a capacity to achieve a balanced vegetative and reproductive growth (Koundouras et al., 2008), which was verified in the present trial. The rarely reported rootstock, '188-08', also showed a better performance in yield than own roots and 'Beta', which was coincident with the result revealed in our previous study on 'Petit Verdot' (Li et al., 2019b). And less vigorous rootstock, '101-14M', markedly reduced the yield, which was referred in a similar research on 'Albarín Negro' grape (Loureiro et al., 2016).

A questionnaire survey (Zhou et al., 2015) reported that 'fresh-looking', 'juicy in mouth', 'sweetness', 'crunchy texture' and 'big berry size' were top five attributes preferred by Chinese consumers over 'price', which indicated that berry quality primarily determines final consumer acceptance. All rootstocks in this paper, especially '110R', reduced berry size. Similarly, Wang et al. (2019) evaluated the effects of rootstocks on 'Cabernet Sauvignon' performance, and berry weight was minimal on '110R'. However, the largest berry mass of 'Marselan' was obtained on '110R' in our previous study (Li et al., 2019a). The different performances of scion varieties on the same rootstock may be related to an explanation proposed by Tandonnet et al. (2009) that the scion and rootstock may differently interact to determine the performance of the grafted plant, which limits a full characterization of the role of the rootstock. While '188-08' produced heavier clusters and similar berry weight and size compared to own roots, which may be due to a larger berry quantity per bunch.

Fruits on '101-14M' retained a high TSS content close to that of non-grafted vines while 'SO4' greatly reduced the berry quality for TSS and TSS/TA, accordant with a previous study on 'Summer Black' (Jin et al., 2016). Besides consensus, contrary effects of same rootstocks on berry quality were revealed surprisingly: Jin et al. (2016) suggested that 'Beta' produced higher TSS and TSS/TA and lower TA as own roots, while '5BB' reduced TSS and TSS/TA, and increased TA greatly. We inferred that soils of different nature might offer element compositions as well as drainage capacities in various levels, which rootstocks would benefit or not, e.g., calcium nitrate (CaN) was the preferred nitrogen form for the rootstock SO4 and ammonium sulphate was the preferred nitrogen form for rootstock 140Ru (Lang et al., 2018). Censi et al. (2014) stated a possible rootstock effect on rare earth elements extraction from the labile soil fraction into the plant. On the other side, berry-cracking and berry shatter, which indicate a shorter shelf life, were more likely to happen in the fruits obtained from '101-14M' and 'SO4' grafted vines respectively, therefore, fruit transportation was limited and local marketing would be appropriate.
The PCA analysis indicated that the comprehensive quality of berry was best in fruits of own-rooted vines. Trees grown on '5BB' and ' $5 \mathrm{C}$ ' also gained better berry qualities, and similar yields to those on own roots, which would be considered as acceptable. Besides, a markedly negative correlation was detected between yield and berry quality related traits: flesh hardness, TSS and compress resistance, indicating a necessary balance between the yield and berry quality. The balance was kept properly in vines on '5BB' and ' $5 \mathrm{C}$ ', while not in vines on 'SO4' for higher yield and lower berry quality and '101-14M' for lower yield and higher TSS. Therefore, a crop control practice like berry thinning might be required for vines on 'SO4' to improve economic traits (Han et al., 2019). Excessive vegetative growth of vines on 'Beta' snatched more nutrition, and resulted in detriment of fruitfulness and quality, based on which vigor control could be considered in further explorations (Bubola et al., 2019).

\section{Conclusion}

Effects of seven rootstocks on tree vigor, fruit yield, and berry quality of 'Summer Black' were varied. Compared with non-grafted vines, grafted ones on 'Beta' gained longer shoots, similar yield, but a worse taste and lower firmness, 'S04' improved trunk diameter and yield, but greatly decreased TSS and texture, '101-14M' decreased yield, berry size, and texture while maintaining vigor and TSS, '188-08' increased fruit yield but with lower TSS and firmness, '110R' showed negative effects on berry size, flavor and texture, and vines on ' $5 \mathrm{BB}$ ' and ' $5 \mathrm{C}$ ' were moderately vigorous and retained equivalent yield and quality attributes.

\section{Acknowledgments}

This work was supported by China Agriculture Research System (CARS-30), Hebei Province Natural Science Foundation (C2019301034 \& C2019301115).

\section{References}

Audeguin, L., Boursiquot, J., and Charmont, S. (2007). Catalogue des Variétés et Clones de Vigne Cultivés en France, $2^{\text {nd }}$ edn. (Montpellier, France: CBE Productions).

Bubola, M., Rusjan, D., and Lukić, I. (2019). Crop level vs. leaf removal: Effects on Istrian Malvasia wine aroma and phenolic acids composition. Food Chem. 312, 126046 (online version). https://doi. org/10.1016/j.foodchem.2019.126046.

Carbonneau, A. (1985). The early selection of grapevine rootstocks for resistance to drought conditions. Am. J. Enol. Vitic. 36(3), 195.

Censi, P., Saiano, F., Pisciotta, A., and Tuzzolino, N. (2014). Geochemical behaviour of rare earths in Vitis vinifera grafted onto different rootstocks and growing on several soils. Sci. Total Environm. 473474, 597-608. https://doi.org/10.1016/j.scitotenv.2013.12.073.

Cheng, D., Chen, J., Gu H., Zhang, W., Zhang, Y., Guo, X., and Jin, L. (2016). Research on grading evaluation about fruit quality of 'Summer Black' grape. J. Fruit Sci. 33(11), 1396-1404. https://doi. org/10.13925/j.cnki.gsxb.20160220.

Colldecarrera, M., Gispert, M.A., and Recio, J.P. (1997). The nutritional status of Chardonnay and Tempranillo in the Alt Empordà area: Effect of rootstock. Acta Hortic. 448, 99-106. https://doi.org/10.17660/ ActaHortic.1997.448.15.

Conradie, W.J. (1983). Liming and choice of rootstocks as cultural techniques for vines in acid soils. S. Afr. J. Enol. Vitic. 4(2), 39-44. https://doi.org/10.21548/4-2-2368.

Corso, M., and Bonghi, C. (2014). Grapevine rootstock effects on abiotic stress tolerance. Plant Sci. Today 1(3), 108-113. https://doi. org/10.14719/pst.2014.1.3.64. 
Cortell, J.M., Sivertsen, H.K., Kennedy, J.A., and Heymann, H. (2008). Influence of vine vigor on Pinot Noir fruit composition, wine chemical analysis, and wine sensory attributes. Am. J. Enol. Vitic. 59(1), 1-10.

Dry, N. (2007). Grapevine Rootstocks: Selection and Management for South Australian Vineyards (Adelaide, S. Australia: Lythrum Press).

Du, Y., Wang, Z., Sun, Q., Zhai, H., and Wang, Z. (2008). Evaluation on grape phylloxera resistance in several grape varieties and rootstocks. Acta Entomol. Sin. 51(1), 33-39. https://doi.org/0.3321/j.issn:04546296.2008.01.006.

Ferris, H., Zheng, L., and Walker, M.A. (2012). Resistance of grape rootstocks to plant-parasitic nematodes. J. Nematol. 44(4), 377-386.

Ferroni, G., and Scalabrelli, G. (1995). Effect of rootstock on vegetative activity and yield in grapevine. Acta Hortic. 388, 37-42. https://doi. org/10.17660/ActaHortic.1995.388.5.

Food and Agriculture Organization of the United Nations (2020). Available online: http://www.fao.org/faostat/en/\#data/QC/ (accessed March 4, 2020).

Gao, D., Bai, R., Lu, X., Wei, Z., and Guo, J. (2015). Study on the cold resistance of five grapevine rootstocks introduced to Shihezi. J. Fruit Sci. 32(2), 232-237. https://doi.org/10.13925/j.cnki. gsxb.20140328.

Gao, Z., Zhai, H., Zang, X., Zhu, H., and Du, Y. (2014). Using differential thermal analysis to analyze grape buds cold hardiness of 8 rootstocks and 6 cultivars. Acta Hortic. Sinica 41(1), 17-25. https:// doi.org/10.3969/j.issn.0513-353X.2014.01.003

Han, W., Han, N., He, X., and Zhao, X. (2019). Berry thinning to reduce bunch compactness improves fruit quality of Cabernet Sauvignon (Vitis vinifera L.). Sci. Hortic. 246, 589-596. https://doi. org/10.1016/j.scienta.2018.11.037.

Jin, Z., Sun, T., Sun, H., Yue, Q., and Yao, Y. (2016). Modifications of 'Summer Black' grape berry quality as affected by the different rootstocks. Sci. Hortic. 210, 130-137. https://doi.org/10.1016/j. scienta.2016.07.023.

Koundouras, S., Tsialtas, I.T., Zioziou, E., and Nikolaou, N. (2008). Rootstock effects on the adaptive strategies of grapevine (Vitis vinifera L. cv. Cabernet-Sauvignon) under contrasting water status: Leaf physiological and structural responses. Agric. Ecosyst. Environm. 128(1), 86-96. https://doi.org/10.1016/j.agee.2008.05.006.

Lang, C.P., Merkt, N., and Zörb, C. (2018). Different nitrogen (N) forms affect responses to $\mathrm{N}$ form and $\mathrm{N}$ supply of rootstocks and grafted grapevines. Plant Sci. (Amsterdam, The Netherlands) 277, 311-321. https://doi.org/10.1016/j.plantsci.2018.10.004.

Li, M., Guo, Z., Jia, N., Yuan, J., Han, B., Yin, Y., Sun, Y., Liu, C., and Zhao, S. (2019a). Evaluation of eight rootstocks on the growth and berry quality of 'Marselan' grapevines. Sci. Hortic. 248, 58-61. https://doi. org/10.1016/j.scienta.2018.12.050.

Li, M., Yan, X., Guo, Z., Jia, N., Yuan, J., Han, B., Yin, Y., Sun, Y., Liu, C., and Zhao, S. (2019b). Rootstock influence on vegetative growth, yield, and fruit quality of 'Petit Verdot'. Eur. J. Hortic. Sci. 84(6), 343-349. https://doi.org/10.17660/eJHS.2019/84.6.3.

Loureiro, M.D., Moreno-Sanz, P., García, A., Fernández, O., Fernández, N., and Suárez, B. (2016). Influence of rootstock on the performance of the Albarín Negro minority grapevine cultivar. Sci. Hortic. 201, 145-152. https://doi.org/10.1016/j.scienta.2016.01.023.

Novello, V., Palma, L., and Bica, D. (1996). Rootstock effects on vegetative-productive indices in grapevine cv. Erbaluce trained to pergola system. Acta Hortic. 427, 233-240. https://doi. org/10.17660/ActaHortic.1996.427.28.

Pavloušek, P. (2009). Evaluation of lime-induced chlorosis tolerance in new rootstock hybrids of grapevine. Eur. J. Hortic. Sci. 74(1), 3541.
Roh, J., Yun, H., Park, K., Lee, C., and Jeong, S. (2003). In vivo evaluation of resistance of grape varieties to crown gall disease. Plant Pathol. J. 19(5), 235-238. https://doi.org/10.5423/ppj.2003.19.5.235.

Romero, P., Botía, P., and Navarro, J.M. (2018). Selecting rootstocks to improve vine performance and vineyard sustainability in deficit irrigated Monastrell grapevines under semiarid conditions. Agric. Water Manag. 209, 73-93. https://doi.org/10.1016/j. agwat.2018.07.012.

Satisha, J., Somkuwar, R.G., Sharma, J., Upadhyay, A.K., and Adsule, P.G. (2010). Influence of rootstocks on growth yield and fruit composition of Thompson Seedless grapes grown in the Pune region of India. S. Afr. J. Enol. Vitic. 31(1), 1-8. https://doi.org/10.21548/31-1-1392.

Sommer, K.J., Islam, M., and Clingeleffer, P.R. (2001). Sultana fruitfulness and yield as influenced by season, rootstock and trellis type. Austr. J. Grape Wine Res. 7(1), 19-26. https://doi. org/10.1111/j.1755-0238.2001.tb00189.x.

Sultan, M. (2016). Effect of rootstocks on growth, yield and fruit quality of Red Globe grape. Ann. Agric. Sci., Moshtohor 54(2), 339344. https://doi.org/10.21608/assjm.2016.104098.

Sun, H., Wang, Z., Fan, X., Liu, C., and Wang, J. (2008). Field evaluation of the resistance of 24 grape germplasms to root-knot nematode. South China Fruits 37(1), 56-59.

Tandonnet, J.P., Cookson, S.J., Vivin, P., and Ollat, N. (2009). Scion genotype controls biomass allocation and root development in grafted grapevine. Austr. J. Grape Wine Res. 16(2), 290-300. https:// doi.org/10.1111/j.1755-0238.2009.00090.x.

United States Department of Agriculture (2019). Fresh Apples, Grapes, and Pears: World Markets and Trade. Available online: https://usda. library.cornell.edu/concern/publications/1z40ks800?locale=en (accessed December 6, 2019).

Vršič, S., Pulko, B., and Kocsis, L. (2015). Factors influencing grafting success and compatibility of grape rootstocks. Sci. Hortic. 181, 168173. https://doi.org/10.1016/j.scienta.2014.10.058.

Walker, R.R., Blackmore, D.H., and Clingeleffer, P.R. (2010). Impact of rootstock on yield and ion concentrations in petioles, juice and wine of Shiraz and Chardonnay in different viticultural environments with different irrigation water salinity. Austr. J. Grape Wine Res. 16(1), 243-257. https://doi.org/10.1111/j.1755-0238.2009.00081.x.

Wang, Y., Chen, W., Gao, X., He, L., Yang, X., He, F., Duan, C., and Wang, J. (2019). Rootstock-mediated effects on Cabernet Sauvignon performance: vine growth, berry ripening, flavonoids, and aromatic profiles. Int. J. Mol. Sci. 20(2), 401. https://doi.org/10.3390/ ijms20020401.

Wang, Z., Zhou, J., Xu, X., Perl, A., Chen, S., and Ma, H. (2017). Adoption of table grape cultivars: An attribute preference study on Chinese grape growers. Sci. Hortic. 216, 66-75. https://doi.org/10.1016/j. scienta.2017.01.001.

Yuan, J., Li, M., Jia, N., Liu, C., Han, B., Yin, Y., Sun, Y., Guo, Z., and Zhao, S. (2019). Evaluation of salt stress tolerance in twenty-one grape rootstocks. Acta Agric. Boreali-occidentalis Sinica 28(4), 602-606. https://doi.org/10.7606/j.issn.1004-1389.2019.04.013.

Zhang, H., Liu, C., Zhong, X., Wang, Z., Sun, H., Fan, X., Liu, X., and Shen, B. (2010). Investigation on population dynamics of grape phylloxera (Daktulosphaira vitifoliae Fitch.) in vineyards of Xi'an and Shanghai. Acta Hortic. Sinica 37(2), 291-296.

Zhang, J., Wu, X., Niu, R., Liu, Y., Liu, N., Xu, W., and Wang, Y. (2012). Cold-resistance evaluation in 25 wild grape species. Vitis 51(4), 153-160. https://ojs.openagrar.de/index.php/VITIS/article/ download/4044/4014

Zhou, J., Cao, L., Chen, S., Perl, A., and Ma, H. (2015). Consumerassisted selection: the preference for new table grape cultivars 
in China. Austr. J. Grape Wine Res. 21(3), 351-360. https://doi. org/10.1111/ajgw.12156.

Received: Mar. 30, 2020

Accepted: Jun. 15, 2020
Address of authors:

Yonggang Yin, Nan Jia, Minmin Li, Changjiang Liu, Junwei Yuan, Bin Han, Yan Sun, Shengjian Zhao and Zijuan Guo*

Institute of Changli Fruit Tree, Hebei Academy of Agricultural and Forestry Sciences, Changli, Hebei, China

* Corresponding author;

E-mail: grapesworks@outlook.com

Tel.: (+86) 3355967149

\section{SUPPLEMENTAL INFORMATION}

SUPPLEMENTAL INFORMATION - TABLE S1. Factor loadings, eigenvalues and variabilities associated with seven principal components (PC) of the PCA of 14 traits related to vigor, yield and quality in 'Summer Black' vines on own roots and 7 rootstocks.

\begin{tabular}{lrrrrrrr}
\hline Traits & PC1 & PC2 & PC3 & PC4 & PC5 & PC6 & PC7 \\
\hline Yield & -0.720 & 0.072 & 0.480 & 0.427 & -0.170 & 0.175 & -0.063 \\
CM & -0.627 & -0.119 & 0.715 & -0.082 & -0.158 & -0.053 & 0.215 \\
BM & 0.334 & 0.250 & 0.799 & 0.084 & -0.378 & -0.185 & -0.046 \\
BL & 0.699 & 0.516 & 0.487 & -0.040 & 0.019 & 0.039 & -0.058 \\
BW & 0.568 & 0.194 & 0.648 & 0.314 & 0.346 & 0.042 & 0.005 \\
BL/BW & 0.397 & 0.599 & -0.070 & -0.506 & -0.459 & -0.010 & -0.107 \\
TSS & 0.780 & -0.172 & 0.215 & -0.087 & 0.533 & -0.154 & -0.015 \\
TA & -0.292 & 0.654 & 0.315 & -0.452 & 0.425 & 0.050 & 0.027 \\
TSS/TA & 0.674 & -0.619 & -0.163 & 0.324 & -0.097 & -0.149 & -0.016 \\
CRB & 0.847 & -0.175 & -0.066 & -0.326 & -0.202 & 0.283 & 0.146 \\
PRC & 0.476 & 0.615 & -0.164 & 0.509 & -0.049 & 0.326 & 0.030 \\
FH & 0.957 & -0.061 & 0.004 & 0.088 & -0.209 & -0.143 & 0.097 \\
MSL & 0.115 & 0.762 & -0.595 & 0.159 & 0.132 & -0.069 & 0.074 \\
N NoS & -0.302 & 0.822 & -0.260 & 0.239 & -0.096 & -0.307 & 0.075 \\
Eigenvalue & 5.103 & 3.253 & 2.667 & 1.326 & 1.115 & 0.425 & 0.111 \\
Variability (\%) & 36.448 & 23.236 & 19.050 & 9.469 & 7.967 & 3.035 & 0.795 \\
Cumulative (\%) & 36.448 & 59.684 & 78.734 & 88.203 & 96.170 & 99.205 & 100.000 \\
\hline
\end{tabular}

CM, cluster mass; BM, berry mass; BL, berry length; BW, berry width; BL/BW, ratio berry length to berry width; TSS, total soluble solids; TA, titratable acid; TSS/TA, ratio total soluble solids to titratable acid; $\mathrm{CRB}$, compression resistance of berry; PRC, pulling resistance of carpopodium; $\mathrm{FH}$, flesh hardness; MSL, mature shoot length; $\mathrm{N}^{\circ} \mathrm{NpS}$, number of nodes per shoot.

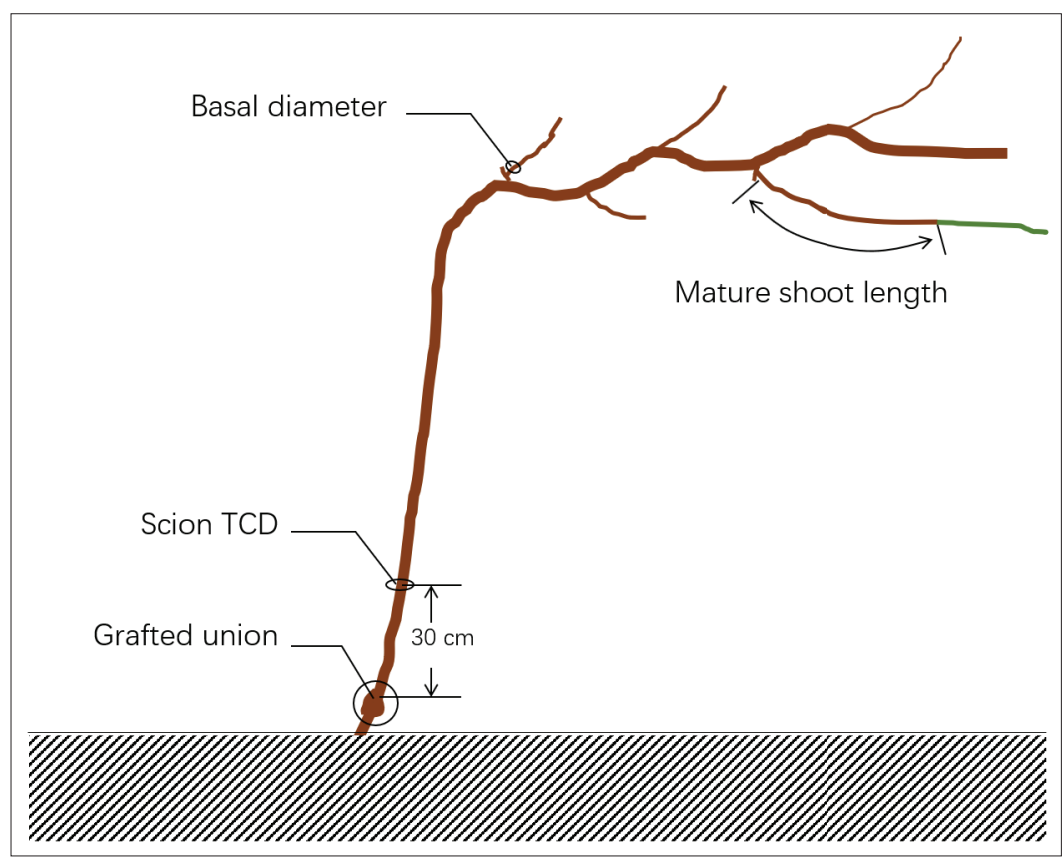

SUPPLEMENTAL INFORMATION -

FIGURE S1. Measuring positions of vine growth parameters. 